\title{
Role of Intravenous Magnesium Sulphate in Term Neonates with Hypoxic Ischemic Encephalopathy (HIE) in a Low-income Country: A Randomised Clinical Trial
}

\author{
Muhammad Asif Siddiqui and Tayyaba Khawar Butt \\ Department of Paediatric Medicine Unit-II, Services Hospital, Lahore, Pakistan
}

\begin{abstract}
Objective: To determine the effects of magnesium sulphate in term neonates with hypoxic ischemic encephalopathy (HIE) in reducing mortality and morbidity.

Study Design: Randomised clinical trial.

Place and Duration of Study: Department of Neonatology, Services Hospital, Lahore, Pakistan from April to December 2019.

Methodology: Term babies (inborn or outborn), fulfilling the operational definition of hypoxic ischemic encephalopathy, reaching within 6 hours of delivery in Nursery Department of Pediatric Medicine Unit-II, Services Hospital, Lahore, were included. Sarnat score was used for staging the severity of HIE. Cases were administered magnesium sulphate (MgSO4) as intravenous infusion. Rest of the management was similar for cases and controls. Mortality was defined as death due to birth asphyxia; whereas, morbidity was assessed by comparing the following at discharge: the grade of hypoxic ischemic encephalopathy, presence and frequency of seizures, duration of seizures, ability to suck feed and neurological problems such as abnormalities of muscle tone and neonatal reflexes. Babies with prematurity, dysmorphism comorbidities or arriving after 6 hours of birth, were excluded. Chi-square test was used for comparison; and $p$ value $<0.05$ was considered significant.

Results: Gender, mode of delivery, mode of resuscitation at birth, major risk factors (prolonged labour, premature rupture of membranes, presence of meconium-stained amniotic fluid) were comparable in both groups. The duration of seizures, ability to suck feed and presence of neurological problems at discharge were significantly better in magnesium sulphate group as compared to control group.

Conclusion: Magnesium sulphate is better in establishing earlier suck feed and reducing the duration of seizures and neurological problems in babies with birth asphyxia.
\end{abstract}

Key Words: Hypoxic ischemic encephalopathy, Magnesium sulphate, Outcome, Term, Low income country

How to cite this article: Siddiqui MA, Butt TK. Role of Intravenous Magnesium Sulphate in Term Neonates with Hypoxic Ischemic Encephalopathy (HIE) in a Low-income Country: A Randomised Clinical Trial. J Coll Physicians Surg Pak 2021; 31(07):817-820.

\section{INTRODUCTION}

In Pakistan, neonatal mortality and morbidity is remarkably high. Birth asphyxia is one of the main contributors to this, apart from prematurity, sepsis and other causes. ${ }^{1,2}$ Birth asphyxia is not only responsible for mortality, but also for short term and long-term neurological complications. Moderate to severe birth asphyxia is responsible for about $40 \%$ mortality and morbidity. ${ }^{3-5}$

Correspondence to: Dr. Muhammad Asif Siddiqui, Department of Paediatric Medicine Unit-II, Services Hospital, Lahore, Pakistan

E-mail: drmasifrmc@gmail.com

Received: April 08, 2021; Revised: June 09, 2021;

Accepted: June 25, 2021

DOI: https://doi.org/10.29271/jcpsp.2021.07.817
Though hypothermia therapy or hypothermia with other adjunct therapies, like magnesium sulphate, has been recommended in moderate to severe hypoxia; but there is no optimal treatment modality available for birth asphyxia in lowincome resource-deprived settings, apart from giving supportive and symptomatic treatment. ${ }^{6}$ Although hypothermia is an established treatment, lack of trained nursing staff is a hindrance in implementing it on a wide scale. Magnesium sulphate is cost-effective and readily available, and is easily administered in comparison to cooling therapy. Because of the relative ease with which it can be used, it may have a beneficial role in management of HIE even in resource-deprived neonatal units. Despite its potential benefit, very few local studies are available on its use.

The objective of this study was to determine the beneficial effects if any, of magnesium sulphate in term neonates with birth asphyxia in terms of morbidity and mortality. 


\section{METHODOLOGY}

It was a randomised clinical trial, conducted in Department of Neonatology, Services Hospital, Lahore from April to December 2019 with total duration of 8 months, after getting approval from Institutional Review Board (IRB/2019/527/SIMS) and Clinical Registry No. NCT04705142. Hypoxic ischemic encephalopathy was defined as need for neonatal resuscitation (rather than stabilisation) at birth with APGAR scores ( $\leq 3$ in 1 minute and $\leq 7$ in 5 minutes). Sarnat scoring was used to grade the severity of hypoxic ischemic encephalopathy (HIE). Mortality was defined as death due to birth asphyxia; whereas, morbidity was assessed by comparing the grade of hypoxic ischemic encephalopathy, frequency of seizures, duration of seizures, ability to suck feed, and neurological problems such as hypotonia/hypertonia, diminished neonatal reflexes at discharge.

All term inborn/outborn babies, reaching within 6 hours of delivery to Department of Neonatology, Services Hospital and fulfilling the operational definition of HIE, were included. Babies with prematurity, dysmorphism and comorbidities, were excluded. Written consent was taken from parents of the babies. This was a single-blinded study. Lottery method was used for randomisation. Cases (Group 1) were given magnesium sulphate with dose of $250 \mathrm{mg} / \mathrm{kg}$ diluted in $10 \mathrm{ml} 10 \% \mathrm{D} / \mathrm{W}$ over 30 minutes in slow infusion at admission, at 24 hours of life and at 48 hours of life, with monitoring vitals (pulse rate, respiratory rate, blood pressure, oxygen saturation, capillary refill time) during and after administration, every 10 minutes. In case of any side effect related to magnesium sulphate, normal saline bolus, calcium gluconate, dopamine, orventilatory support was provided as per ward policy. Baseline serum magnesium level was done before first dose than at day 2, day 3, and day 4 . Controls (group 2) received similar supportive and symptomatic treatment with regular monitoring as control group. All data were taken on pre-designed proforma. SPSS version 23 was used to analyse the data. The data were expressed with frequencies and percentages. Chi-square test was used, and value less than 0.05 was taken as significant.

\section{RESULTS}

Forty babies were included in group 1(Magnesium sulphate/case group) and 40 babies in group 2 (control group), after excluding one baby due to comorbid condition (congenital heart disease). Two babies (one in each group) left against medical advice (consort flow diagram Figure 1 ).

In order to minimise bias, the authors compared gender, mode of delivery, mode of resuscitation at birth and major risk factors (prolonged labour, premature rupture of membranes, meconium-stained amniotic fluid) between two groups; and found no difference ( $p$ value $>0.05$ ). However, the weight for gestation was significantly lower in the control group ( $p$-value $<0.05$; Tablel).

Comparing outcomes in both groups, duration of seizures, suck feed at discharge, neurological status at discharge were significantly better in group 1 (magnesium sulphate group). Whereas, grade of HIE, frequency of seizures at discharge, and mortality were comparable in both groups (Table I). No side effects were noted related to intravenous magnesium sulphate infusion; likewise no significant variability in magnesium sulphate serum level detected between the two groups.

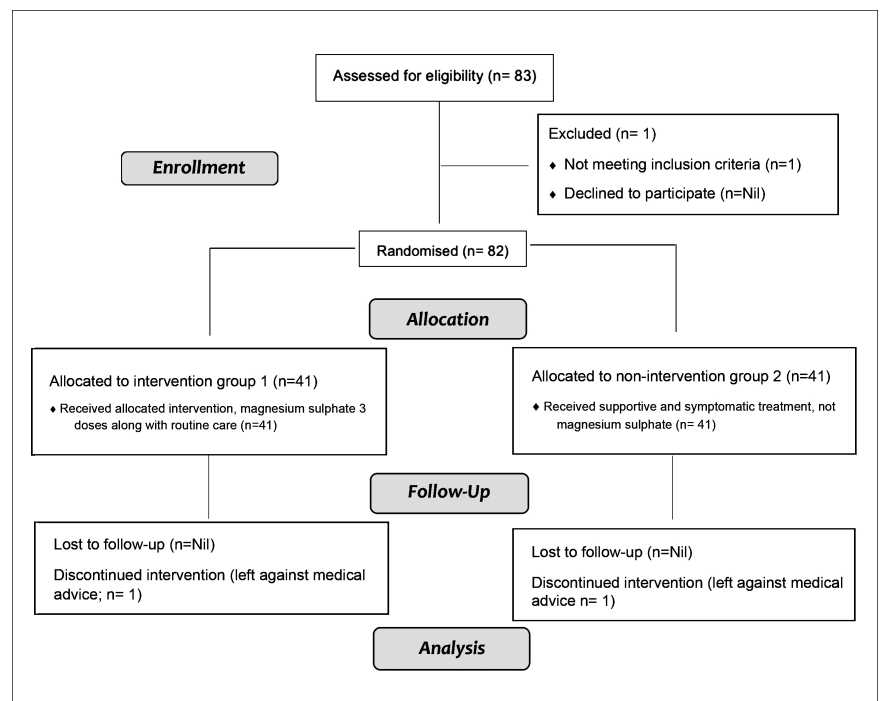

Figure 1: Consort 2010 flow diagram.

\section{DISCUSSION}

Neonatal mortality rate is very high in Pakistan; and birth asphyxia is one of the main contributors. ${ }^{1,2}$ Most units provide supportive and symptomatic care to babies with HIE due to resource limitations. Although body cooling is of definite benefit, most units in resource-limited settings are unable to provide it, because of lack of manpower in terms of numbers and training. Magnesium sulphate is cost-effective, readily available therapy with potential benefit in babies with HIE. However, sufficient local data is not available. Therefore, the authors felt the need to conduct this study to determine its safety and efficacy in resource limited settings

Magnesium sulphate use in HIE with hypothermia and other adjunct therapies is well established and it has shown improvements in short term outcomes with good safety profile. However, it has not shown significant improvement in long term outcomes and mortality. ${ }^{7-14}$

Internationally, there are many studies to support magnesium sulphate as monotherapy along with supportive care in HIE. Many of them showed short term beneficial effects in terms of reducing the duration of seizures, early establishment of suck feed, better short-term neurological outcomes. ${ }^{7,9,14-16}$ This study also showed similar results in terms of reduction in duration of seizures, early establishment of suck feed, better tone and neonatal reflexes in the absence of significant side effects. However, mortality, grade of HIE, frequency and presence of seizures were similar in both groups. Other patient characteristics, like gender, mode of delivery, major risk factors and mode of resuscitation, were comparable in both groups. Majority of babies were delivered by C-section with major risk factor being fetal distress or premature rupture of membranes. 


\begin{tabular}{|c|c|c|c|c|}
\hline Parameter & Parameter category & Cases & Control & p-value \\
\hline Gender & $\begin{array}{l}\text { Male } \\
\text { Female }\end{array}$ & $\begin{array}{l}20(50 \%) \\
20(50 \%)\end{array}$ & $\begin{array}{l}21(52.5 \%) \\
19(47.5 \%)\end{array}$ & 0.823 \\
\hline Mode of delivery & $\begin{array}{l}\text { SVD* } \\
\text { c-section } \\
\text { Assisted vaginal delivery }\end{array}$ & $\begin{array}{l}12(30 \%) \\
27(67.5 \%) \\
1(2.5 \%)\end{array}$ & $\begin{array}{l}17(42.5 \%) \\
23(57.5 \%) \\
0(0 \%)\end{array}$ & 0.336 \\
\hline Risk factors & $\begin{array}{l}\text { Meconium-stained liquor } \\
\text { PROM* } \\
\text { Prolonged labor } \\
\text { Others }\end{array}$ & $\begin{array}{l}8(20 \%) \\
9(22.5 \%) \\
14(35 \%) \\
9(22.5 \%)\end{array}$ & $\begin{array}{l}7(17.5 \%) \\
8(20 \%) \\
16(40 \%) \\
9(22.5 \%)\end{array}$ & 0.968 \\
\hline Weight for gestation & $\begin{array}{l}\text { AGA* } \\
\text { SGA* } \\
\text { LGA* }\end{array}$ & $\begin{array}{l}29(72.5 \%) \\
4(10 \%) \\
7(17.5 \%)\end{array}$ & $\begin{array}{l}27(67.5 \%) \\
11(27.5 \%) \\
2(5 \%)\end{array}$ & 0.047 \\
\hline Resuscitation & $\begin{array}{l}\text { PPV* with mask } \\
\text { PPV with ETT* } \\
\text { PPV with ETT \& } \\
\text { chestcompression }\end{array}$ & $\begin{array}{l}18(45 \%) \\
8(20 \%) \\
14(35 \%)\end{array}$ & $\begin{array}{l}22(55 \%) \\
10(25 \%) \\
8(20 \%)\end{array}$ & 0.323 \\
\hline HIE* Grade & $\begin{array}{l}\text { III } \\
\text { II }\end{array}$ & $\begin{array}{l}5(12.5 \%) \\
20(50 \%) \\
15(37.5 \%)\end{array}$ & $\begin{array}{l}6(15 \%) \\
13(32.5 \%) \\
21(52.5 \%)\end{array}$ & 0.276 \\
\hline Seizures & Present & $31(77.5 \%)$ & $33(82.5 \%)$ & 0.576 \\
\hline Frequency of seizures & $\begin{array}{l}\text { Single } \\
\text { Multiple }\end{array}$ & $\begin{array}{l}9(22.5 \%) \\
22(55 \%)\end{array}$ & $\begin{array}{l}6(15 \%) \\
23(57.5 \%)\end{array}$ & 0.663 \\
\hline Duration of seizures & $\begin{array}{l}<48 \text { hours } \\
>48 \text { hours }\end{array}$ & $\begin{array}{l}10(25 \%) \\
15(37.5 \%)\end{array}$ & $\begin{array}{l}2(5 \%) \\
19(47.5 \%)\end{array}$ & 0.043 \\
\hline Suck feed at discharge & Present & $27(67.5 \%)$ & $16(40 \%)$ & 0.004 \\
\hline Neurological status & Normal & $26(65 \%)$ & $15(37.5 \%)$ & 0.007 \\
\hline Outcome & $\begin{array}{l}\text { Survived } \\
\text { Expired }\end{array}$ & $\begin{array}{l}30(75 \%) \\
10(25 \%)\end{array}$ & $\begin{array}{l}26(65 \%) \\
14(35 \%)\end{array}$ & 0.329 \\
\hline
\end{tabular}

Final analysis revealed a significantly greater number of small for gestational age neonates in the control group, which may lead to possible bias in the outcome.

Although there were only those babies who were less than 6 hours of age at admission, some studies have reported significant reduction in mortality and other beneficial effects of magnesium sulphate, even if given between 6 to 24 hours of life. ${ }^{17,18}$

Regional studies also report significant role of magnesium sulphate in reducing the seizures duration and early establishment of suck feed. However, not all researchers have addressed the possible confounding factors. ${ }^{15,16,19-22}$

Limitations of this study include small sample size, significant difference in weight for gestation between the two groups, and absence of long-term follow-up of neuro-developmental outcomes in babies who survived in both groups.

\section{CONCLUSION}

Magnesium sulphate is safe and has beneficial effects in establishing earlier suck feed, control of seizures, and better neurological status at discharge. It may be included in the routine management of babies, especially in resourcelimited nurseries. However, further studies are required to see long term advantage of $\mathrm{MgSO}_{4}$.

ETHICAL APPROVAL:

Ethical approval was obtained before start of study with reference No. IRB/2019/527/SIMS from Institutional Review Board (IRB) of Services Institute of Medical Sciences, Lahore.

\section{PATIENTS' CONSENT:}

Patients' consents were obtained from the parents of the babies before enrolling them in the study.

\section{CONFLICT OF INTEREST:}

The authors declared no conflict of interest.

\section{AUTHORS' CONTRIBUTION:}

MAS, TKB: Conception, design of the work, analysis, interpretation of data, drafting, critical revision, and final approval of version to be published.

\section{ACKNOWLEDGEMENT:}

Dr. Fatima Tahira (Assistant Professor of Pediatrics, Pediatric Medicine, Services Hospital, Lahore) helped in collection of data.

\section{REFERENCES}

1. Aghai ZH, Goudar SS, Patel A, Saleem S, Dhaded SM, Kavi A, et al. Gender variations in neonatal and early infant mortality in India and Pakistan: A secondary analysis from the Global Network Maternal Newborn Health Registry. Reprod Health 2020; 17(3):178. doi.org/10.1186/ s12978-020-01028-0.

2. Ahmed M, Won Y. Cross-national systematic review of neonatal mortality and postnatal newborn care: Special focus on Pakistan. Int J Environ Res Publ Health 2017; 
14(12). doi: 10.3390/ijerph14121442.

3. Midan DA, Researcher I, View P. Oral allopurinol for preventing mortality and morbidity in neonates with moderate hypoxic ischemic encephalopathy. 2017;(April).

4. Yıldız EP, Ekici B, Tatlı B. Neonatal hypoxic ischemic encephalopathy: An update on disease pathogenesis and treatment. Expert Rev Neurother 2017; 17(5):449-59. doi.org/ 10.1080/14737175.2017.1259567.

5. Shamaoon M, Razzaq N, Ahsan M, Ahmad A, Maqbool T, Chaudhary AJ. Electrolyte imbalance in neonates with hypoxic ischemic encephalopathy: A single center study. Prof Med J 2020; 27(10):2159-64. doi: http://doi.org/10.29309/TPMJ/2020.27.10.4128.

6. Zen Lee CY, Chakranon P, Huey Lee SW. Comparative efficacy and safety of neuro-protective therapies for neonates with hypoxic ischemic encephalopathy: A network meta-analysis. Front Pharmacol 2019; 10:1221. doi: 10.3389/fphar.2019.01221.

7. Lingam I. Magnesium sulphate neuroprotection in neonatal encephalopathy. 2020.

8. Anabrees J. Magnesium sulphate for newborns with HIE; synopsis of evidence from a systematic review. J Clin Neonatol 2013; 2(3):114-6. doi: 10.4103/2249-4847. 119989.

9. Lingam I, Robertson NJ. Magnesium as a neuroprotective agent: A review of its use in the fetus, term infant with neonatal encephalopathy, and the adult stroke patient. Dev Neurosci 2018; 40(1):1-12. doi: 10.1159/000484891.

10. Nair J, Kumar VHS. Current and emerging therapies in the management of hypoxic ischemic encephalopathy in neonates. Children (Basel) 2018; 5(7):99. doi: 10.3390/children5070099.

11. Montaldo P, Lally PJ, Oliveira V, Swamy R, Mendoza J, Atreja $\mathrm{G}$, et al. Therapeutic hypothermia initiated within 6 hours of birth is associated with reduced brain injury on MR biomarkers in mild hypoxic-ischaemic encephalopathy: $A$ non-randomised cohort study. Arch Dis Child Fetal Neonatal Ed 2018; 104(5):F515-F520. doi: 10.1136/archdischild2018-316040.

12. El Farargy MS, Soliman NA. A randomised controlled trial on the use of magnesium sulfate and melatonin in neonatal hypoxic ischemic encephalopathy. J Neonat Perinat Med
2020; 12(4):379-84. doi: 10.3233/NPM-181830.

13. Nonomura M, Harada S, Asada $Y$, Matsumura $H$, Iwami $H$, Tanaka $Y$, et al. Combination therapy with erythropoietin, magnesium sulfate and hypothermia for hypoxic-ischemic encephalopathy: An open-label pilot study to assess the safety and feasibility. BMC Pediatr 2019; 19(1):13. doi: 10.1186/s12887-018-1389-z.

14. Ichiba H, Tamai $H$, Negishi $H$, Ueda $T$, Kim TJ, Sumida $Y$, et al. Randomised controlled trial of magnesium sulfate infusion for severe birth asphyxia. Pediatr Int 2002; 44(5): 505-9. doi: 10.1046/j.1442-200x.2002.01610.x.

15. Sreenivasa B, Lokeshwari K, Joseph N. Role of magnesium sulphate in management and prevention of short term complications of birth asphyxia. Sri Lanka J Child Heal 2017; 46(2):148-51.

16. Riyaz Ahmed FK, Shrikanth SN. Evaluation of safety of magnesium of sulphate therapy in neonates with birth asphyxia. Int J Contemp Pediatr 2016; 3(1):80-5. doi: http://dx.doi.org/10.18203/2349-3291.ijcp20160095.

17. Pius S, Bello M, Ambe JP, Yenti M, Genesis R, Clement AY, et al. Magnesium sulphate treated severely asphyxiated neonates, their characteristic and outcome. Asian J Pediatr Res 2019; 1(July 2018):1-9.

18. Okonkwo I, Okolo A. Postnatal magnesium sulfate in asphyxiated newborns in benin city nigeria: Effect on mortality. Int J Pediatr Neonatal Care 2018; 4(1). doi:10.15344/24552364/2018/136.

19. Savitha MR, Rajprakash. Beneficial effect of intravenous magnesium sulphate in term neonates with perinatal asphyxia. Int J Contemp Pediatr 2016; 3(1):150-4. .doi.org/10.18203/2349-3291.ijcp20160149

20. Muhammad H, Ahmad I. Role of magnesium sulphate in newborns with birth asphyxia. J Med Physiol Biophys 2019; 54:115-8.

21. Sajid NK, Junaid M, Ahmed S. Therapeutic efficacy of magnesium sulphate on neurological outcome of neonates with severe birth asphyxia. J Univ Med Dent Coll 2018; 9(4):1-5. Available from: http://www.jumdc.com/index.php/jumdc/ article/view/95.

22. Rashid A, Fatima N, Asim M, Khalid A, Ali AS. Role of magnesium sulphate in short term neurological outcome of perinatal asphyxia. Pakistan Postgrad Med J 2015; 26(1):1-5. 